\title{
Is There A Quick Path For Valuation Of Ecosystem Services?-A Comparative Study In Xiu River, China
}

\author{
Tongyang Wei, and Yong Yang \\ Agricultural Information Institute of CAAS,Beijing,China
}

\begin{abstract}
This paper uses the valuation of Xiu River Hydrological Regulating services in Jiangxi province, China as a case study to compare 3 methods to value the ecosystem services, i.e improved contingent valuation method, choice based conjoint analysis and special benefit transfer method. Willingness to pay is estimated by using Logit and Clogit with contrasting controls for non-protests residents. This study discusses the implications of these findings and direction for related future researches into the ecosystem services valuation in China. Appropriate methods should be used for different valuation proposes, rather than blindly using special benefit transfer method just for its convenience. China should construct Ecosystem services value table based on Chinese case studies.
\end{abstract}

\section{Introduction}

In the past 30 years, China's economy has developed rapidly, with natural resources excessive consumption and destruction. In recent years, Chinese government has paid more and more attentions on natural resources development and protection, which leads to increasing demand of ecosystem services valuation. Assessment of ecosystem services in China can be traced back to 1982([1]).Case studies of ecosystem services assessment are also increasing rapidly, but most scholars prefer to use special benefit transfer methods for convenience. (Special benefit transfer starts from the result of paper entitled the value of the world's ecosystem services and natural capital, written by Costanza, printed on nature 1997([2])). Gaodi Xie, a Chinese scholar, updates the table in the mentioned above paper. The updated table is called Chinese terrestrial ecosystem unit area Ecosystem services value table $([3,4])$. Chinese scholars use the value of this table to evaluate ecosystem services. It is effective to raise public's awareness, but it is not good for policy decision-making, and the results and accuracy need to be considered.

The comparative studies of valuation methods include comparison of direct market method and statement preference method, comparison of revealing preference method and stated preference method, comparison of different stated preference method, comparison of benefit transfer method(BTM) and stated preference method. Most of the comparative studies of the statement preference method are the comparison between contingent valuation method (CVM) and choice experiment method (CE). The comparative studies of CVM and the joint analysis method do not show obvious regularity in the valuation difference. There are fewer cases of comparison between benefit transfer method and other valuation methods. Most of the comparative cases are value-comparison cases. There are few studies that compare different valuation methods in terms of their applicability, practice, rationale, and accuracy of evaluation.

From the perspective of methodology, application, implementation and accuracy, different valuation methods have their own advantages and disadvantages. We attempt to use different methods to evaluate the value of the same case, and try to further analyze different methods from the perspective of evaluation principle, evaluation application process, trial scope, convenience, and accuracy. Based on the demand and special usage background, a case study conducted in Xiu River. More precisely, we address the following questions,(1) Present and discuss ecosystem services valuation methods used in china;(2)Present and discuss the results of different methods including CVM, Special BTM, choice-based conjoint analysis(CBC); (3) Give some feasible proposals on improving methods and usage in China.

\section{Case study site}

Xiu River is located in the northwest of Jiangxi province and belongs to Poyang Lake water system. It is one of the five major rivers in Jiangxi province and the mother river of Jiujiang people. Xiu River originates from Tonggu County, which flows through Xiushui County, Wuning County and Yongxiu County, and has been intercepted by Zhelin Reservoir at Zhenlin town Yongxiu County. As the largest adjustment Xiu River reservoir, Zhelin Reservoir has the characteristics of good water quantity abundant, strong regulation and others. The water quality stays between first Class and second Class, which is better than that of Yangtze River. Jiujiang urban 
district is located at downstream Xiushui basin, with municipal water from the Yangtze River. In order to get more safety water, Jiujiang municipality plans to drink the Xiushui water form Zhelin Reservoir as the municipal water replace Yangtze water.

\section{Methods}

First of all, we learned about the actual situation of water use in Jiujiang and Zhelin Lake through group discussion with local residents and government. And three methods are used including contingent valuation method, choice-based conjoint analysis method and special benefit transfer method in this study. contingent valuation method and choice-based conjoint analysis are based on the fieldwork survey. Special benefit transfer method is based on the results of other studies and land use conditions.

\subsection{Contingent valuation method}

We conducted a survey on services benefit areas in June 2013. The questionnaire consists of five parts. The first part is project overview survey area conditions. The second part includes conditions of drinking water source, identifications of ecosystem services provide by Xiu River, family awareness of source water quality, environmental awareness and whether from chronic diseases patient's family. The third part is respondents' willingness to pay question, consists of CVM and CBC. The fourth part is basic information of respondents, including age, sex, job, education, revenue, Hukou and whether long-term residence. The fifth part is investigator assessment section, which assesses the seriousness of the respondents to answer questions and provides a reference for the reliability of data.

1080 questionnaires were conducted at Dean County, Xingzi County, Jiujiang County and Jiujiang urban district. The method of Stratified Random Sampling was adopted in the questionnaire distribution. Before formal investigation, a pilot study of 32 respondents is conducted. According to the pre-survey, we determine the underlying value (CNY per household per month), $2,5,10,15,20,30$. There are two major types of elicitation techniques used in this CVM study, namely, Single-bounded dichotomous choice (DC)with choice options "Yes", "No", "Not sure", payment card. These two techniques combined into a new special double-bounded dichotomous choice method, which is closer to real market. According to the choices, we transfer the payment card to three different single-bounded DC, using double-bounded DC Logit model to analyze.

\subsection{Choice based conjoint analysis}

According to the pre-survey, we determine the underlying value (CNY per household per month), 20, 10, 0 . On the basis of pre-investigation and Orthogonal Design from SPSS, we identify four selections, including maintaining the status selection. Water quality ranges from First Class to Second Class, and water supply stability are different. See Table 1 for details. With clogit model analyzing the $\mathrm{CBC}$ data, we get the results of $\mathrm{CBC}$. The results of $\mathrm{CBC}$ are compared with the results of CVM, and verify with elicitation technique of the CVM at the same time.

Table 1. Different scenario sets

\begin{tabular}{|c|c|c|c|c|}
\hline Attributes & Scenario A & Scenario B & Scenario C & Scenario D \\
\hline Quality & $\begin{array}{c}\text { Increased to class } \\
\text { I water }\end{array}$ & $\begin{array}{c}\text { Maintaining class II } \\
\text { water }\end{array}$ & $\begin{array}{c}\text { Increased to class } \\
\text { I water }\end{array}$ & $\begin{array}{l}\text { Maintaining class } \\
\text { II water }\end{array}$ \\
\hline Quantity & Stable & Unstable & Stable & Unstable \\
\hline $\begin{array}{l}\text { Payment(CNY per } \\
\text { month per household) }\end{array}$ & 20 & 10 & 10 & 0 \\
\hline
\end{tabular}

\subsection{Special benefit transfer method}

This section consists of two small parts, including transfer Xiegaodi method and transfer costanza method. Different with previous special BTM case studies, in this study, we add more factors, such as social economic factor, biomass factor coefficient, payment preferences coefficient, water quality and quantity factor coefficient, GDP factor and purchasing power parity.

\subsubsection{Transfer Xie gaodi's Method}

According to equivalent value per unit area of ecosystem services in china by Xiegaodi and Xiu River adjustment factors, we get equivalent value per unit area of ecosystem services in Xiu River. Xiu River adjustment factor include water quality and quantity coefficient, biomass factor coefficient, socio-economic factor coefficient, payment preferences coefficient, ability to pay coefficient. Through researches and consultation with relevant experts, the Xiu River water quality and quantity correction coefficient is defined as 2.4. We use farmland ecosystem biomass factor instead of Xiu river ecosystem biomass factor because of the data availability. Thus biomass factor coefficient is 1.51 . According to the formula, the payment preferences coefficient is 0.76 obtained by formula. Ability to pay is defined as the ratio of per capita GDP in Jiujiang and national per capita GDP. Ability to pay coefficient is 0.59 .We adjust national equivalent value through adjustment factors, and get Xiu River equivalent table. 
Table 2. Equivalent per unit area of ecosystem services in Xiu River (2012)

\begin{tabular}{cccccccc}
\hline Services & Services & Woodlands & Grasslands & wetlands & Rivers/lakes & farmlands & Deserts \\
\hline $\begin{array}{c}\text { Regulating } \\
\text { Services }\end{array}$ & $\begin{array}{c}\text { Hydrological } \\
\text { Regulating }\end{array}$ & 3.64 & 1.35 & 0.69 & 28.76 & 40.14 & 0.06 \\
\hline
\end{tabular}

\subsubsection{Transfer Costanza's Method}

According to summary of average global value of annual ecosystem services table, China and global biomass factor coefficient, China and the global socio-economic factor coefficient, exchange rate and purchasing power parity, we get the table of ecosystem services value per unit area in china. Because there are not enough cases of desert, the value of desert is not listed. Farmland and cities are man-made systems, so farmland and cities are not represented in the ecosystem value table.

Table 3. Water supply and regulation average global value of annual ecosystem services ( $\$ /$ ha/year, 2007 price levels, De Groot 2012)

\begin{tabular}{ccccc}
\hline Biome & Inland wetlands & Rivers/lakes & Woodlands & Grasslands \\
\hline $\begin{array}{c}\text { Hydrological } \\
\text { Regulating services }\end{array}$ & 6,014 & 1,808 & 560 & 60 \\
\hline
\end{tabular}

Key: source from R De Groot,L. Brander, van der Ploeg, S., Costanza, etc. Global estimates of the value of ecosystems and their services in monetary units. Ecosystem Services, 2012,1: 50-61([5])

Through the adjustment of exchange rate coefficient of annual average year, social ability to pay, purchasing power parity and GDP index, we get the table of equivalent per unit area of ecosystem services in Xiu River (Table 4 for details).

Table 4. Equivalent per unit area of ecosystem services in Xiu River（CNY/ha/year, 2012)

\begin{tabular}{lcccc}
\hline \multicolumn{1}{c}{ Biome } & Inland wetlands & Rivers/Lakes & Woodlands & Grasslands \\
\hline $\begin{array}{l}\text { Hydrological } \\
\text { Regulating services }\end{array}$ & 26660.35 & 8014.96 & 1034.38 & 110.83 \\
\hline
\end{tabular}

\section{Results}

We get different services value of Xiu River upstream by using different valuation methods, 14.43 billion CNY with improved Xie Gaodi's equivalency factors method, 1.313 billion CNY with transfer Costanza's new research method, 38 million CNY with CVM double boundary dichotomous, and 53 million $\mathrm{CNY}$ with $\mathrm{CBC}$ method. The conclusions from different methods vary widely.

\subsection{CVM valuation analysis}

According to different defining types of the first Single-bounded dichotomous choice "not sure" option, we get three different data distribution. According to the first single-bounded dichotomous choice value and payment card value, "Not sure" is defined as "Yes" or "No" in the analysis of Type A. "Not sure" is defined as "Yes" in the analysis of type B. "Not sure" is defined as "No" in the analysis of type C.

Table 5. Estimation results for Logit Models

\begin{tabular}{cccc}
\hline Variable & Model A & Model B & Model C \\
\hline Constant & $1.939^{* * *}(0.00)$ & $2.110^{* * *}(0.00)$ & $1.925^{* * *}(0.00)$ \\
Bid & $-0.153^{* * *}(0.00)$ & $-0.153^{* * *}(0.00)$ & $-0.153^{* * *}(0.00)$ \\
Mean WTP & 13.486 & 14.421 & 13.407 \\
(CNY/month/household) & & & 38.081 \\
Total WTP & 38.306 & 40.961 & 1080 \\
(Million CNY per year) & 1080 & 1080 & \\
Number of respondents & & & \\
\hline
\end{tabular}

Notes: ${ }^{* * *}=$ significant at the $1 \%$ Level, Bid=questionnaire payment value, Probability values in parentheses.

Total willingness to pay does not significantly vary among Models A, B and C.It reflects that the design of first single-bounded dichotomous choice "not sure" option is less meaningful. It is important to add "do not know" option in the segment of whether to enter the hypothetical market, through comparison of self-assessment question for uncertainty of respondents' payment amount and $\mathrm{CBC}$ two sections. According to Jiujiang's total annual willingness to pay formula, the total willingness to pay is the product of the mean willingness to pay (median) and the agreed payment probability, the total number of households and the number of months. Finally, we estimated upstream Xiu River provides 38 million CNY worth of Hydrological Regulating services annually.

\subsection{CBC valuation analysis}


Table 6. Estimation results for Clogit Models

\begin{tabular}{lcccc}
\hline \multirow{2}{*}{ Variable } & \multicolumn{2}{c}{ Protest and non-protest residents } & \multicolumn{2}{c}{ Non-protest residents } \\
\cline { 2 - 5 } & Basic & Interactive & Basic & \multicolumn{1}{c}{ Interactive } \\
\hline$\Delta \mathrm{q}$ & $-5.2054^{* * *}$ & $-5.3041^{* * *}$ & $3.9575^{* * *}$ & $3.772^{* * *}$ \\
\multirow{2}{*}{$\Delta S$} & $(-3.94)$ & $(-3.96)$ & $(2.48)$ & $(2.33)$ \\
Bid & $-4.3317^{* * *}$ & $-4.3699^{* * *}$ & $4.8311^{* * *}$ & $4.7106^{* * *}$ \\
& $(-3.36)$ & $(-3.35)$ & $(3.07)$ & $(2.96)$ \\
Mean WTP & $0.5425^{* * *}$ & $0.5353^{* * *}$ & $-0.3737^{* *}$ & $-0.3733^{* *}$ \\
(CNY/month/household) & $(3.99)$ & $(3.87)$ & $(-2.29)$ & $(-2.26)$ \\
$\quad$ Total WTP & 17.57 & 17.54 & 23.52 & 23.18 \\
(Million CNY per year) & 52.964 & 52.873 & 70.899 & 69.875 \\
Number of respondents & 1040 & 1040 & 929 & 929 \\
\hline
\end{tabular}

Notes: $\mathrm{Bid}=$ questionnaire payment value, ${ }^{* * *}=$ significant at the $1 \%$ Level on $Z$ test, $Z$ values in parentheses.

Responses are analyzed by Clogit model. The Clogit model estimation results show that each variable passes the test of significance. The sign of the variable is consistent with the expected direction. The higher the respondents' income is, the more receptive to the stability of water quality and water stability is. Total willingness to pay does not significantly vary between income cross-term model and non-income cross-term model. It reflects that there is little effect whether join the income cross-term or not. Total willingness to pay of non-protest response is higher than that of all basic responses. According to Jiujiang's total annual willingness to pay formula, the total willingness to pay is the product of the mean willingness to pay (median) and the agreed payment probability, the total number of households and the number of months. Finally, we estimate upstream Xiu River provides 53 million CNY worth of hydrological regulating services annually.

\subsection{Transfer Xie gaodi's method valuation analysis}

According to the land use in the upstream Xiu River and equivalent per unit area of ecosystem services in Xiu River, we get the water regulation value of upstream Xiu River. Table 7 shows the value of upstream Xiu River, which is based on benefit transfer Xie Gaodi method with a series of indicators modification. Finally, we estimate upstream Xiu River provides 14.4 billion CNY worth of hydrological regulating services annually.

Table 7. Summary of water supply and regulation value of annual upstream Xiu river ecosystem services $\left(10^{7} \mathrm{CNY} \cdot \mathrm{hm}^{-2} \cdot \mathrm{a}^{-1}, \mathrm{year}^{\mathrm{of}}\right.$ 2012)

\begin{tabular}{cccccccc}
\hline Area & Summary & Forest & Grass & Cropland & Wetlands & River/lake & Desert \\
\hline Total & 1442.85 & 710.19 & 28.38 & 37.64 & 37.12 & 629.12 & 0.40 \\
\hline
\end{tabular}

\subsection{Transfer Costanza's method valuation analysis}

According to the land use in the upstream Xiu River and equivalent per unit area of ecosystem services in Xiu River, we get the water regulation value of upstream Xiu
River. Table 8 shows the value of upstream Xiu River, which is based on benefit transfer Costanza method with a series of indicators modification. Finally, we estimate upstream Xiu River provides 1.3 billion CNY worth of hydrological regulating services annually.

Table 8. Summary of water supply and regulation value of annual upstream Xiu River ecosystem services $\left(10^{7} \mathrm{CNY} \cdot \mathrm{hm}^{-2} \cdot \mathrm{a}^{-1}, \mathrm{year}^{\mathrm{of}}\right.$ 2012)

\begin{tabular}{cccccccc}
\hline Area & Summary & Forest & Grass & Cropland & Wetlands & River/Lake & Desert \\
\hline Total & 131.25 & 72.55 & 0.84 & -- & 12.45 & 45.40 & -- \\
\hline
\end{tabular}

\section{Conclusion}

In this study, contingent valuation method, choice based conjoint analysis method and special benefit transfer method are used to evaluate Xiu river water regulation services. Questionnaires are administered to a sample of households in downstream Xiu River. Random utility model estimation is used to establish valuations of water quality and stability services. We get different results in different ways. The results obtained from contingent valuation method and choice based conjoint analysis method do not significantly vary, however, the results by the above methods vary widely with that obtained from special benefit transfer method. The result derived from stated preference method such as double-bounded CVM is much lower than that of Benefit transfer Costanza method, which is 375 times less than the result obtained from transfer Xie Gaodi method and 33 times less than the result from transfer Costanza method. The research conclusion of Qiao Xiuning $([6,7])$ is similar with our study. For evaluating Wei Gan River, CVM and transfer Xie Gaodi method are used in his study. He find that the result derived from transfer Xie gaodi method is much higher than that derived from CVM, with a gap nearly 440 times. 


\section{Discussions}

The valuation of Xiu River water quality and stability services significantly varies between benefit transfer Xie Gaodi method and benefit transfer Costanza method, which reflect low accuracy in the special benefit transfer method. There may be several reasons, such as estimated item differences, method's own deficiencies, differences in method principles, errors in reference cases and overestimation of equivalence values.

Regarding the accuracy of the evaluation method, Li Jinchang points out that in the exploration of environmental valuation methods, it is necessary to solve the problem from scratch, and then gradually solve the problem from rough to fine ([8]). With the development of evaluation technology, there are both rough estimation techniques and accurate evaluation techniques in the existing value assessment techniques. Different technologies can be selected as needed. Costanza also pointed out that the range of applications for value assessment based on different accuracy is different. The accuracy of choosing a value assessment technique depends on the purpose of the value assessment application. Generally speaking, regardless of the scale of evaluation from the region to the world, if the purpose of the assessment is to raise public awareness and make people aware of the huge value of ecosystem services, it requires less accurate technology. However, the accuracy of the technology in the specific policy analysis, the value accounting in the ecological compensation project and the cost accounting project varies from medium to high.

The evaluation of large-scale ecosystem services has important practical significance for understanding the value of natural capital on the national scale, provincial scale and municipal scale. However, the guiding significance of large-scale value assessment for environment and ecosystem management in small areas is not clear and direct ([9]). The evaluation of small-scale ecosystems such as provincial and municipal, district and county at the administrative level, the key river basins and protected areas at the natural regional level are important value assessment directions ([10]).

Therefore, in the need for accurate valuation, benefit transfer is a good choice. It is easy to calculate a rough value, which is also served as a warning. When it is necessary to estimate the value accurately, such as an ecological compensation project, the compensation amount needs to be determined according to the evaluation of ecosystem services. In this case, it is advocated to use Statement preference method (CVM or $\mathrm{CBC}$ and etc) to investigate the benefit or the loss group, but the questionnaire should be designed reasonably to avoid a series of deviations such as hypothetical deviation, yes deviation and strategic deviation.

This study illustrates that values in quick way vary widely. It is effective to raise public's awareness, but it is not good for decision-making. Appropriate methods should be used for different valuation proposes, rather than blindly using Special benefit transfer method just for its convenience. China should construct Ecosystem services value table based on Chinese case studies not the table transfer from Xie Gaodi. Social, economic, ecological variables should be listed in case study analysis for benefit transfer.

\section{References}

1. J.B Zhang. Preliminary studies on forest benefits calculated on the basis of theory and procedures. Forest Resources Management, 17(3):1-5(1982)

2. R Costanza, R d' Arge, R de Groot, S Farber, M Grasso, The value of the world' $s$ ecosystem services and natural capital. Nature, 387: 253-60(1997)

3. G.D Xie,C.X Lu, Y.F Leng.Ecological assets valuation of the Tibetan Plateau.Journal of Natural Resources. 18(2):189-196(2003)

4. G.D Xie,l Zhen, C.X Lu,Y Xiao,C Chen, Expect knowledge based valuation method of Ecosystem services in China. Journal of Natural Resources. 23(5):911-919(2008)

5. R.De Groot, , L Brander, S van der Ploeg, R Costanza,., F Bernard, Braat, L., Christie, M., Crossman, N., Ghermandi, A., Hein, L., Hussain, $\mathrm{S}$, Global estimates of the value of ecosystems and their services in monetary units. Ecosystem Services, 1: 50-61(2012)

6. X.N Qiao, Y.J Yang, D.G Yang. Assessment of Ecosystem Services Value Transfer in Weigan River Basin,xinjiang,China.Journal of Desert Research, 1(4): 1008-1014(2011)

7. X.N Qiao, Y.J Yang, D.G Yang. Willingness to pay for ecosystem services and influencing factors in Weigan River Basin. Chinese Journal of Eco-Agriculture, 20(9):1254-1261(2012)

8. J.C Li, Ecological value theory, Chongqing science press,30(1999)

9. Millennium Ecosystem Assessment: Biodiversity synthesis report. Washington D C: World Resources Institute, (2005)

10. J Zhao,K Yang. Research progress on ecosystem services value assessment. Acta Ecologica Sinica, 27(1):346-356(2007) 